\title{
Strategic approach to environmental management: case of Russian chemical enterprise
}

\author{
Aleksandr Kozlov ${ }^{1, *}$, Irina Zaychenko ${ }^{1}$, and Anna Smirnova ${ }^{1}$ \\ ${ }^{1}$ Peter the Great St. Petersburg polytechnic University, Institute of Industrial Economics, Management \\ and Trade, 195251 St. Petersburg, Russian Federation
}

\begin{abstract}
The article substantiates the need to integrate environmental aspects in a balanced scorecard (BSC) to improve the efficiency of environmental management system at chemical plants. For environmental management, the balanced scorecard serves as a convenient management tool that is able to provide relevant and timely information on the environmental aspects of the refinery.
\end{abstract}

\section{Introduction}

One of the characteristic features of the current stage of development of the productive forces of society is the "chemization" of the techno sphere [1], which is typical for most developed and developing countries of the world, and this is confirmed by the fact of growth of sales of chemical products in the world in 2017 compared to 2016 by $4.6 \%$ [2]. In Russia, the chemical industry is one of the most important sectors of the economy, so in 2015 the volume of chemical production, production of coke and petroleum products amounted to $29.4 \%$ of the total number of products of all production sectors of the Russian economy (calculated by [3]). However, the chemical industry in Russia, unfortunately, also makes a significant contribution to the aggravation of environmental problems, producing significant amounts of different types of waste. In terms of the volume of waste generated in the industry of chemicals and chemical products along with petrochemicals and coke production, in 2017, the second place among all processing industries $(52,286.9$ million tons of waste), second only to metallurgy (150,802.2 million tons) [4]. Management of environmental control processes is a complex technical and organizational task that requires the use of effective strategic management tools, modern technologies and technical means to monitor a wide range of indicators that reflect the level of environmental safety in the chemical industry, including indicators aimed at the use of modern information management technologies and technical means of environmental control.

* Corresponding author: alyovina@gmail.com 
Thus, the purpose of the study, the results of which are presented in this article, is the use of a strategic approach to environmental management and the development of a strategic map of environmental control management in the chemical industry, taking into account the use of modern information technologies and technical means of monitoring and collection of environmental information.

To achieve this goal, the following tasks were solved.

- Analysis of the status and relevance of the problem of improving environmental management for the chemical industry in Russia.

- Analysis of tools for strategic management of environmental management processes in modern enterprises.

The choice of the tool of strategic management of processes of ecological management in the chemical industry is proved.

- Development of a strategic map of environmental management processes using modern information technologies and technical means of monitoring and collecting environmental information.

- Identification of indicators reflecting, inter alia, the use of modern information technologies and technical means for monitoring and collecting environmental information.

- Approbation of the use of the strategic map on the example of the service of the chief ecologist of a large chemical production.

Two types of production facilities were chosen as the object of research - the chemical enterprise and the oil pipeline to the refinery. With regard to chemical production, modern methods of environmental control should be divided into the following main components Organizational arrangements - the establishment of independent structural units with responsibility for environmental protection; the development of an appropriate normative and methodological documentation; interaction with the relevant government agencies; conduct activities of preventive character, including training on the protection of the environment in the organization and training seminars for employees.

Technical measures-the introduction of modern methods of control and diagnosis of hazardous production; the use of modern SOFTWARE (artificial intelligence) for real-time monitoring and "predictive" management.

All of these components are fairly well analyzed in various REFERENCE studies. In this work, the emphasis will be placed on the use of modern methods of environmental monitoring and data collection - the use of drones and "Swarm" technologies. And if the latter are still in the stage of laboratory research, then the use of single drones has already gained a lot of experience and statistical material.

Drones one of the important technical means of dramatically improving the quality of one of the main tasks of the environmental service is the monitoring of the surrounding space, the use of which can dramatically increase both the speed of obtaining information in real time and the number of controlled factors.

In the petrochemical industry, unmanned aerial vehicles are used to solve the following tasks [1]:

- systematic monitoring of pipelines;

- monitoring the condition of pipelines

- regular control of industrial production at each stage of the working process;

- timely detection of oil spills;

- identification of areas of outlet pipeline and the deviation from the calculated position;

- detection of violations of requirements for protection of pipeline sections, monitoring of near-pipe space and ground facilities;

- prospecting and exploration 
- environmental monitoring of atmospheric emissions

- remote control of surveys and contract works

- operational control over unauthorized actions and stay of unauthorized persons at the protected facilities, as well as detection of illegal closure of the pipeline, illegal activities, theft.

For these purposes, unmanned aerial vehicles are equipped with equipment for photo and video shooting. Shooting is performed using the camera mounted on the UAV. The camera is used for more rapid visual inspection of the territory along the route of the oil trunk pipeline. Unlike video, photography has the advantage of higher resolution. In addition to photo and video, there is also thermal imaging. Such a survey allows monitoring in conditions of limited visibility (e.g. fog) or at night. Combining different types of shooting allows you to more accurately assess the condition of the object. In this case, the operator can manually change the trajectory of the unmanned aerial vehicle, return it to the desired point and take a picture of the object again.

In the future, unmanned aerial vehicles can be used not only for monitoring industrial facilities, but also for direct Troubleshooting. For example, in the competition" Drones for Good", held in the Arab Emirates, the first place was taken by the development, which is intended for use in industrial facilities, in particular, for monitoring of land pipelines. However, the functions of the device do not end there. The uniqueness of the development is that it performs work to eliminate the identified problems, for example, sealing damage in the pipe of the gas or oil pipeline. Patches are made of liquid polyurethane foam. The device applies the material to the place of depressurization, within 5 minutes it solidifies and closes the gap [2].

Most of the oil companies of the Russian Federation are already using unmanned aerial vehicles for the purpose of regular monitoring of oil pipelines. Taking into account the specific characteristics of the area in which oil and gas companies are engaged in their activities, it can be concluded that the use of unmanned aerial vehicles makes it possible to monitor and detect problems in the operation of industrial facilities much faster.

\section{Materials and methods}

All aspects of environmental control of industrial enterprises in General and chemical enterprises in particular are in the focus of numerous researchers. The study [5] proposes a game on environmental protection of chemical plants, which is focused on the authorities responsible for environmental protection and helps them in their current management work. The authors [6] investigated the role of ecological sample banks as a tool for monitoring the presence of various chemicals (polybrominated diphenyl ethers, perfluorinated compounds, alkylphenol compounds, ORGANOTIN compounds, etc.) in various ecological systems and revealed the usefulness of the sample Bank in the management of chemicals. The study [7] focuses on the concept of "green" management for small and medium-sized enterprises of the polymer industry. The paper [8] describes a system for monitoring the safety of chemical materials based on radio frequency identification (RFID) and data collection (AIDC) technology, spatial database technology and web technology. However, the purpose of the system is to achieve operational rather than strategic objectives, primarily to reduce the risk of emergency response in the logistics system of dangerous goods. In work [9] the mathematical model of linear programming for a choice of optimum technical schemes of decrease of atmospheric pollutants in relation to the Chinese oil-refining and chemical enterprises is developed. 
However, the research used in the strategic approach to environmental management is limited. For example, article [10] examines the sustainable development of chemical enterprises, analyzes the relationship between sustainable development and competitiveness, taking into account the specifics of the chemical industry. The study identified links between human capital development and the competitiveness of the chemical industry. However, the study does not propose precise indicators for monitoring in strategic control in environmental management. The authors [11] proposed a system of environmental management accounting (EMA), which presents the results of the experience of adaptation and integration of environmental management accounting in the framework of strategic management of enterprises. The limitation of the EMA system is determined by the fact that it includes only accounting data. It does not cover other important indicators related to environmental management and control.

M. E. Dillon in [12] describes integrated data management systems that combine data on ecology, health and safety, implemented at two chemical plants. Nevertheless, the article does not specify the indicators characterizing the environment, focuses on competitive advantages and analyzes how this system can strengthen the overall viability of the enterprise and its relationship with stakeholders.

The authors in [13] present an approach to environmental management based on the concept of a set of regional indicators, but applied it to regional management rather than enterprise management.

Analyzing the methods and tools of strategic management, allowing to take into account environmental aspects, it is possible to distinguish Pestel analysis in a standard form in relation to waste management [14] or in combination with other tools, such as scenario approach [15] and the concept of balanced assessment maps (BSC) [16], developed By R. Kaplan and D. Norton. Pestel analysis of the business environment contains a second "e", consisting of environmental factors to be monitored and analyzed. BSC is a more advanced tool for strategy formulation; in addition, the idea of the strategic map proposed in [17] allows developing indicators characterizing environmental problems and modern tools for monitoring and collecting information. Environmental indicators are part of the component of the strategic map "entrepreneurship and business" proposed in [17].

\section{Results}

Thus, due to the lack of research and proposals on practical tools for the implementation of the strategic approach to environmental management, the task of developing a strategic map for the component "entrepreneurship and business", including environmental indicators based on modern information technologies and methods of monitoring data collection important in strategic decision-making, is relevant.

The strategic map of the enterprise constructed on the basis of the concept of SSP represents the modern tool of management of the enterprise where all its elements are defined by the General concept of digital transformation of economy as a whole and consider characteristic features of each of components of classical model of BCS.

$\mathrm{BSC}$ is one of the strategic management tools that allows formalizing the company's strategic goals and further decomposing them to the level of operating activities and main business processes. The key levels of decomposition are the following groups of indicators:

- Finance (financial performance)

- Customer (sales figures)

- Internal business processes (process performance indicators)

- Learning and growth (training and development indicators) 
At all levels, the control of the balanced scorecard (BSC) is carried out through the so called Key Performance Indicator (KPI) - Key performance indicators.

The first perspective includes traditional financial indicators. No matter how we prove the importance of the market orientation of the enterprise and the perfection of internal processes, the owner will always be primarily interested in the indicators of financial return on investment. Therefore, a balanced system should start (in the classification) and end (in the final evaluation) with financial indicators.

The second perspective describes the external environment of the company, its relationship with customers. The main focuses of attention are:

- ability of the enterprise to customer satisfaction;

- ability of the enterprise to retain the client;

- ability to acquire a new customer;

- market share in the target segment.

- The third perspective describes business processes (business operations):

- the level of equipment and technologies used in comparison with the most advanced;

- portfolio of measurements performed and the period of their implementation;

- direct and indirect indicators are commonly used in the design of a system for measuring innovation and enterprise development. Direct indicators estimate:

- novelty and efficiency of the implemented technologies (in comparison with the world, industry or regional level);

- number of innovations and improvements introduced;

- the cost of technical re-equipment;

- investment in information technology. Indirect indicators-most often assess the effectiveness of human resources:

- re-training and retraining costs per employee;

- labour productivity growth;

- number of innovative and innovative proposals;

- emissions from industrial activities;

- administrative processes, such as tariff setting, environmental inspection, technical supervision, litigation, etc

The fourth perspective describes the ability of the enterprise to learn, develop and innovate, which focuses on the following factors:

- people with their abilities, including potential skills and motivation;

- information systems to deliver real-time information;

- organizational procedures that ensure interaction between participants in the process and determine the decision-making system

The solution to the problem of sustainable environmental development is possible in the case of using a program-target approach, which involves the development of a set of regional indicators (CRI). The system of balanced scorecard proposed By R. Kaplan and D. Norton was adopted as a basic methodology for the development [16]. According to the General strategic map of development of chemical enterprises, the solution of issues related to ensuring sustainable environmental development and increasing the level of environmental safety applies to all components, as shown in the diagrams (Fig. 1). 


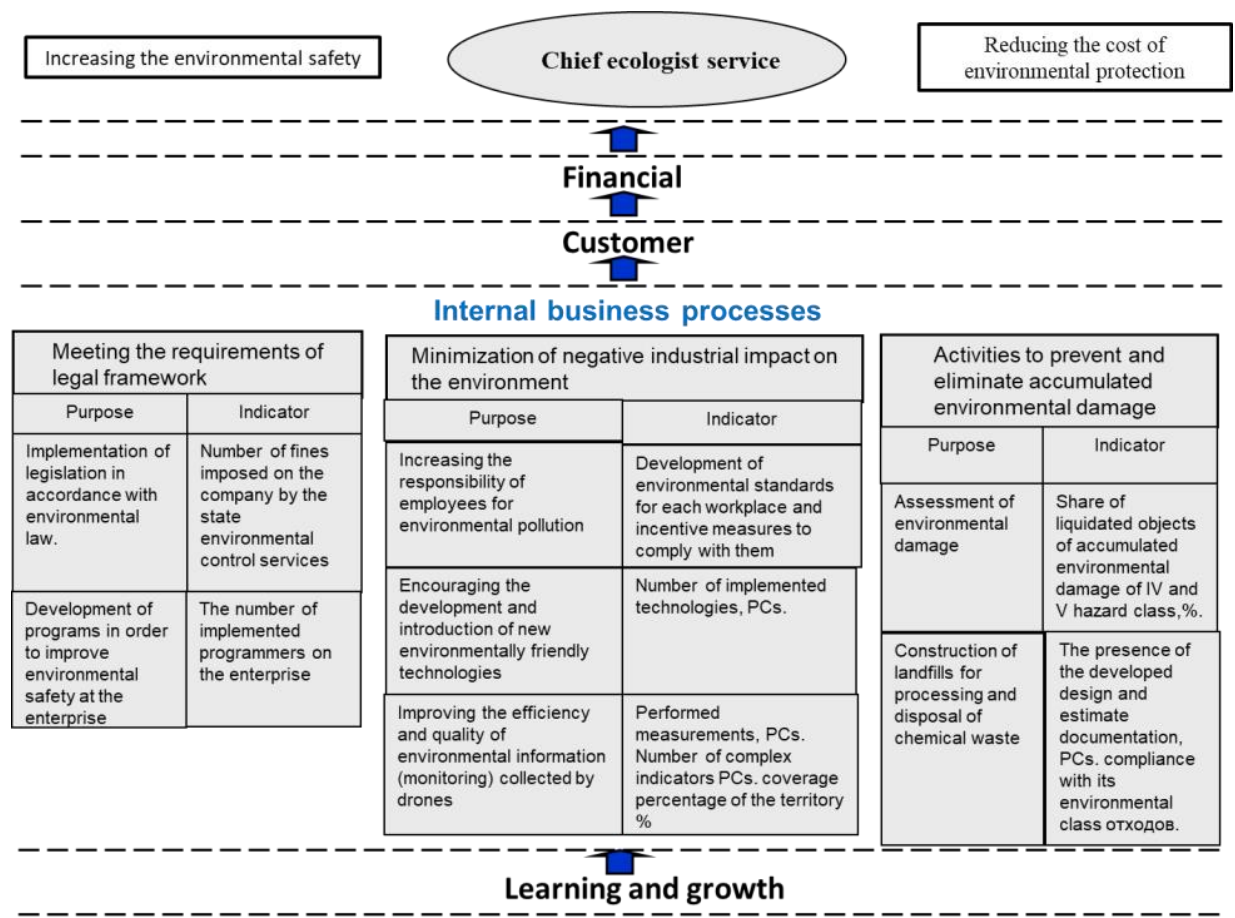

Fig. 1. Balanced scorecard strategic map of internal business environmental service

\section{Discussion}

The BSC creates a link and feedback between strategic objectives and specific business processes, reflects both monetary and non-monetary performance, which is especially important in environmental management. For example,it may reflect the following environmental aspects: compliance with regulations technical operation and operating modes, the level of compliance with environmental safety standards, environmental impact indicators (emissions of greenhouse gases and other pollutants into the atmosphere, the volume of liquid waste indicating the quality of wastewater, the total mass of solid waste,etc.), the safety of oil products supplies to consumers, the quality of oil products.

Currently, all over the world there are very serious environmenta requirements for petroleum products, which are aimed at reducing the content of benzine benzene, aromatic hydrocarbons, sulfur. In this regard, the classical perspective of the BSC needs to be supplemented. In particular, the perspective of "Stakeholders, customers, consumers" of the refinery development strategy should be evaluated and on the environmental side, including the indicators presented in table 1

Table 1. Environmental indicators for monitoring the chemical enterprise in the BSC

\begin{tabular}{|l|l|}
\hline Indicators & Indicators \\
\hline $\begin{array}{l}\text { Number of fines imposed on the company by } \\
\text { the state environmental control services }\end{array}$ & Annual payout amount in environmental fines \\
\hline
\end{tabular}




\begin{tabular}{|l|l|}
\hline $\begin{array}{l}\text { The number of the implemented programmes } \\
\text { on the enterprise }\end{array}$ & Number of innovative programs \\
\hline $\begin{array}{l}\text { Development of environmental standards for } \\
\text { each workplace and incentive measures to } \\
\text { comply with them }\end{array}$ & $\begin{array}{l}\text { The number of the implemented programmes in } \\
\text { the structuring of personal motivation }\end{array}$ \\
\hline $\begin{array}{l}\text { Performed measurements, PCs. Number of } \\
\text { complex indicators PCs. coverage percentage } \\
\text { of the territory \% }\end{array}$ & Amount of information received and processed \\
\hline $\begin{array}{l}\text { The presence of the developed design and } \\
\text { estimate documentation, PCs. compliance with } \\
\text { its environmental class }\end{array}$ & $\begin{array}{l}\text { Relevance and compliance with environmental } \\
\text { legislation }\end{array}$ \\
\hline
\end{tabular}

Depending on the degree of pollution the level of environmental impact is estimated in points from 1 to 5 . Accordingly, the higher the negative impact on environment, the lower the score. In addition to the main indicators, the environmental component of oil refineries activities is characterized by: emission of nitrogen oxides, sulfur dioxide and other oxides into the atmosphere the amount of accumulated oily waste and waste catalysts; fines, penalties for violation of environmental legislation.

\section{Conclusion}

The strategic maps of sustainable environmental development proposed in this study make it possible to create a set of indicators, the constant monitoring of which forms an information field for assessing the current state and dynamics of the environmental situation at the chemical enterprise. As a result there is the possibility of establishing a system of monitoring the condition and pollution of the environment, using modern monitoring tools terrestrial, aircraft integrated with existing and established international systems for monitoring the environment and providing detection and forecast of dangerous and extreme natural events, including adverse climate change.

\section{References}

1. S.G. Gorshenin, Environmental responsibility oil and gas enterprises. 250 p. (Saratov, Emirit, 2017)

2. http://www.cefic.org/Documents/RESOURCES/Reports-and-

Brochure/Cefic_FactsAnd_Figures_2018_Industrial_BROCHURE_TRADE.pdf. (Last accessed 03.04.2019)

3. http://www.gks.ru/free_doc/doc_2016/prom16.pdf(Last accessed 03.04.2019)

4. http://www.gks.ru/free_doc/new_site/oxrana/tabl/oxr_otxod1-okved2.xls accessed 03.04.2019)

5. Z. Zhu, B. Chen, G. Reniers, L. Zhang, S. Qiu, X. Qiu, Playing chemical plant environmental protection games with historical monitoring data. International Journal of Environmental Research and Public Health. 14(10), \# 1155, (2017)

6. J. Koschorreck, C. Heiss, J. Wellmitz, A. Fliedner, H. Rüdel, The use of monitoring data in EU chemicals management-experiences and considerations from the German 
environmental specimen bank. Environmental Science and Pollution Research. 22(3), Pages 1597-1611 (2015)

7. E. Vasileva, Y. Hristova-Pesheva, D. Ivanova, Green business management as Business opportunity for small and medium-size enterprises in polymer industry. Journal of Chemical Technology and Metallurgy, 53(4), pp. 773-781 (2018)

8. Y. Wang, The design and implementation of the safety monitoring system of the chemical dangerous goods logistics based on RFID technology ICMTEL 2016 - 1st EAI International Conference on Multimedia Technology and Enhanced Learning2 8 February 20171st EAI International Conference on Multimedia Technology and Enhanced Learning, ICMTEL 2016

9. X.C. Li, J. Y. Wen, J. Long, X.Y. Du, Y. Li. Emission reduction potential optimization model on refinery and chemical enterprises for atmospheric pollutants total amount control. Applied Mechanics and Materials. 472, pp. 904-908 (2014)

10. J. Hyršlová, L. Vnoučková, M. Hájek, Concept of sustainable development and competitiveness of enterprises in chemical industry. Chemicke Listy, 109(4), pp. 317336 (2015)

11. L. Constantin, M. Teodorescu, Implementation of environmental management accounting systems in Romanian companies methodology and case studies Journal of Environmental Protection and Ecology, 13(1), pp. 319-324 (2012)

12. M. E. Dillon, Enterprise best practices for strategic environmental, health and safety data management. Proceedings of the Air and Waste Management Association's Annual Conference and Exhibition, AWMA, 6, pp. 3569-3572 (2008)

13. A. Kozlov, S. Gutman, I. Zaychenko, E. Rytova, P. Nijinskaya. Environmental management on the basis of Complex Regional Indicators Concept: case of the Murmansk region. IOP Conference Series: Materials Science and Engineering 6, 91(1), 012073 (2015)

14. R. Walsh, Dealing with uncertainties of environmental change by adding scenario planning to the strategy reformation equation. Management Decision. 43, 1, pp. 113$122(2005)$

15. Jinbo Song, Yan Sun, Lulu Jin. PESTEL analysis of the development of the waste-toenergy incineration industry in China. Renewable and Sustainable Energy Reviews, 80, pp. 276-289 (2017)

16. R. Kaplan, D. Norton, The balanced scorecard: translating strategy into action Harvard: Harvard Business Press, 322 p. (1996)

17. R. Kaplan, D. Norton, Strategy maps: Converting intangible assets into tangible outcomes. Boston: HBS Press, 467 p. (2004) 